\title{
Transcranial magnetic stimulation and preparation of visually-guided reaching movements
}

\section{Pierpaolo Busan ${ }^{1 *}$, Marco Zanon ${ }^{2}$, Federica Vinciati ${ }^{1}$, Fabrizio Monti ${ }^{3}$, Gilberto Pizzolato ${ }^{3}$ and Piero P. Battaglini ${ }^{1}$}

1 BRAIN, Center for Neuroscience, Department of Life Sciences, University of Trieste, Trieste, Italy

2 Department of Medical and Biological Sciences, University of Udine, Udine, Italy

${ }^{3}$ Department of Medical, Surgical and Health Sciences, University of Trieste, Trieste, Italy

Edited by:

Giovanni Mirabella, University of La Sapienza, Italy

Reviewed by:

Hun-Kuk Park, Kyung Hee

University, South Korea

Patrizia Fattori, University of

Bologna, Italy

Giovanni Mirabella, University of La

Sapienza, Italy

\section{*Correspondence:}

Pierpaolo Busan, BRAIN, Center for Neuroscience, Department of Life Sciences, University of Trieste, Via Fleming 22, Trieste 34127, Italy. e-mail:pbusan@units.it
To better define the neural networks related to preparation of reaching, we applied transcranial magnetic stimulation (TMS) to the lateral parietal and frontal cortex. TMS did not evoke effects closely related to preparation of reaching, suggesting that neural networks already identified by our group are not larger than previously thought. We also replicated previous TMS/EEG data by applying TMS to the parietal cortex: new analyses were performed to better support reliability of already reported findings (Zanon et al., 2010; Brain Topography 22, 307-317). We showed the existence of neural circuits ranging from posterior to frontal regions of the brain after the stimulation of parietal cortex, supporting the idea of strong connections among these areas and suggesting their possible temporal dynamic. Connection with ventral stream was confirmed. The present work helps to define those areas which are involved in preparation of natural reaching in humans. They correspond to parieto-occipital, parietal and premotor medial regions of the left hemisphere, i.e., the contralateral one with respect to the moving hand, as suggested by previous studies. Behavioral data support the existence of a discrete stream involved in reaching. Besides the serial flow of activation from posterior to anterior direction, a parallel elaboration of information among parietal and premotor areas seems also to exist. Present cortico-cortical interactions (TMS/EEG experiment) show propagation of activity to frontal, temporal, parietal and more posterior regions, exhibiting distributed communication among various areas in the brain. The neural system highlighted by TMS/EEG experiments is wider with respect to the one disclosed by the TMS behavioral approach. Further studies are needed to unravel this paucity of overlap. Moreover, the understanding of these mechanisms is crucial for the comprehension of response inhibition and changes in prepared actions, which are common behaviors in everyday life.

Keywords: movement execution, parietal cortex, premotor cortex, reaching, transcranial magnetic stimulation, TMS/EEG co-registration

\section{INTRODUCTION}

Several works have tapped on neural underpinnings of reaching movement preparation, focusing on parieto-frontal circuits (e.g., Andersen and Buneo, 2002; Andersen and Cui, 2009; Cisek and Kalaska, 2010). In particular, reaching movements under visual guidance are prepared using different information which is elaborated in different frames of reference. These are, for example, eye-, limb-, body- or head-centered (Cohen and Andersen, 2002; Beurze et al., 2010) using visual as well as proprioceptive information (Buneo et al., 2002; Filimon et al., 2009; Jackson et al., 2009). Since preparation of reaching movements involves the activation of a fronto-parietal network (Tannè et al., 1995; Johnson et al., 1996; Galletti et al., 2001; Marconi et al., 2001; Gamberini et al., 2009; Bakola et al., 2010; Passarelli et al., 2011), it has been hypothesized that it integrates information about physical properties and location of a target into the motor plan of a reaching movement (Buneo et al., 2002; Cohen and Andersen,
2002). In fact, Milner and Goodale (2006) suggested the existence of a dorsal stream that mediates sensory-motor transformations for visually-guided movements overlapping with the above mentioned anatomic regions. They also suggested the existence of a ventral stream, which would be more involved in the elaboration of object's features primarily involving occipito-temporal regions.

An unsolved issue regarding implementation of reaching movements is related to the possible dominance of one hemisphere, preferably the left one (Goodale, 1988), usually viewed as the dominant hemisphere in right-handed people (e.g., Iacoboni, 2006; Vingerhoets et al., 2011). Thus, the left hemisphere likely plays a special role in organizing movements during visuallyguided reaching (Goodale, 1988). The contralateral limb may be more represented during planning of reaching, activating a wide series of neural networks (e.g., Kertzman et al., 1997; Medendorp et al., 2003, 2005). The activation of both hemispheres in similar tasks (Calton et al., 2002; Connolly et al., 2003; Prado et al., 2005) 
or of structures modulated by ipsilateral reaching has also been reported (Chang et al., 2008; Busan et al., 2009b). However, in our previous and present investigations, we mainly concentrated on the left hemisphere of subjects using their right hand, considering that this should allow to individuate the better representation of neural circuits for reaching (see above).

By stimulating medial parieto-occipital, parietal and premotor regions with TMS, we have previously identified a discrete network of regions that were involved in the preparation of reaching movements (Busan et al., 2009a,c). Specifically, at the start of preparation, we induced a facilitation in reaction time (RT) in a medial parieto-occipital region near the parieto-occipital sulcus, independently of the use of foveal or peripheral vision, and independently of the target position (however, strongest effects were observed for foveal vision and central reaching). Moreover, the stimulation of a region close to the posterior parietal cortex resulted in slower RT when TMS was delivered at about half of the preparatory process, affecting only central reaching. This same region was facilitated (showing faster reaction times) when stimulating at the start of reaching preparation. This was explained by the state-dependent theory of TMS (Silvanto and Muggleton, 2008): the TMS effect may strongly depend on the excitability of the stimulated region. Referring to our data, TMS could "pre-activate" cortical regions at the start of the preparatory process before their effective involvement in the stream, facilitating their intervention. In contrast, when cortical regions are already involved in the task, the adjunction of "neural noise" (Miniussi et al., 2010) may interfere with their correct functioning and, consequently, a slower elaboration of information may result.

When stimulating at about half of the mean RT in a more anterior left parietal region (around the intraparietal sulcus), we were able to induce an additional shortening of RT, facilitating the preparation of reaching (Busan et al., 2009a). Moreover, we were able to evoke a similar effect stimulating the left premotor dorsal cortex, in the same time window, suggesting a parallel processing of information in these cortical regions (Busan et al., 2009a).

We have now extended the mapping of cortical areas possibly involved in preparing visually-guided reaching movements. We tested whether the application of TMS to regions more laterally located in comparison to previous ones will affect the reaching movement preparation. Occipital, parietal and premotor cortices were stimulated. Negative results would have implied that the preparation of natural reaching is strictly related to structures in the superior parietal lobule (SPL). This should support the hypotheses of a "dorso-medial" stream that is preferentially involved in reaching movements, classically opposed to a "dorso-lateral" stream, possibly more devoted to grasping and/or reach-to-grasp movements (Jeannerod et al., 1995; Davare et al., 2006, 2010; Koch et al., 2010). On the contrary, if TMS would have elicited any effect, this would suggest a wider extent of the stream and a role for some of its more lateral regions in the preparation of reaching (Koch et al., 2008; Vesia et al., 2008, 2010; Reichenbach et al., 2011).

We also were interested in understanding the relations among cortical regions possibly involved in the preparation of reaching. Using a TMS/Electroencephalography (EEG) co-registration approach, we individuated an ensemble of areas recruited by stimulation of the left parietal cortex (putatively around the intraparietal sulcus) that comprises areas of the temporo-occipital regions (i.e., the ventral stream; Zanon et al., 2010). This confirms an interchange of information between dorsal and ventral streams, and that they are not segregated systems (e.g., Schenk and Milner, 2006; Borra et al., 2008), adding information about the temporal dynamics of this activity.

We also wished to further characterize the temporal dynamics of activation elicited by stimulation of the previously investigated region (Zanon et al., 2010), thus we used a TMS/EEG co-registration approach replicating that experiment, but adopting different analyses. Slightly different, but compatible findings were expected that would strengthen the previous conclusions.

A better understanding of the circuitry involved in the preparation of reaching is important for practical purposes such as, for example, the implementation of rehabilitative protocols or prosthetic devices. Moreover, the understanding of the organization and physiology of response inhibition could be helped by the knowledge of the physiology and organization of unrestrained reaching movements.

\section{MATERIALS AND METHODS BEHAVIORAL TMS STUDY Subjects}

A total of 58 healthy subjects underwent TMS over different cortical regions, as reported in Table 1. Subjects were right-handed (Edinburgh Inventory; Oldfield, 1971). Participants gave written informed consent after receiving information about TMS, in compliance with the Declaration of Helsinki and the Ethics Committee of the University of Trieste. Participants could leave the study at any time, although all completed the experiments. These statements apply also to TMS/EEG procedures.

\section{Cortical stimulation}

TMS was delivered over three brain regions of the left hemisphere: five scalp locations were in parietal cortex, four in premotor cortex, and one in parieto-occipital cortex. For each location, TMS was delivered at three different times during preparation of reaching: $25 \%$ of mean reaction time (m-RT), $50 \%$ of $\mathrm{m}-\mathrm{RT}$, and $75 \%$ of m-RT (Table $\mathbf{1})$.

TMS (Medtronic MagPro R30) was delivered through a figureof-eight coil (diameter of each wing about $7 \mathrm{~cm}$ ), oriented tangentially to the scalp (single pulse stimulation; biphasic waves; pulse duration: $280 \mu \mathrm{s}$ ). The coil was secured on the scalp by hand and position was checked and readjusted if necessary. The coil was maintained with a $45^{\circ}$ orientation with respect to the inter-hemispheric fissure with the handle pointing downward and backward.

Subject's heads were not restrained, although participants were asked to maintain a stable position for the entire experiment. The stimulation coil was maintained in position even when no TMS was delivered.

Stimulated scalp positions, were determined according to an adapted EEG coordinate system (e.g., Herwig et al., 2003; Jurcak et al., 2007) and using a probabilistic method (Steinsträter et al., 2002; http://www.neuro03.uni-muenster.de/ger/t2tconv/). Points of stimulation were marked on a cap. Stimulated points with the 
Table 1 | Stimulated areas and subjects recruited for the behavioral experiments.

\begin{tabular}{|c|c|c|c|c|c|}
\hline \multirow{2}{*}{$\begin{array}{l}\text { Stimulated cortical region } \\
\text { (left hemisphere) }\end{array}$} & \multirow{2}{*}{$\begin{array}{l}\text { Time of stimulation } \\
\text { (\% of } \mathrm{m}-\mathrm{RT} \text { ) }\end{array}$} & \multicolumn{4}{|c|}{ Subjects } \\
\hline & & $N$ & males/females & Age range & $\begin{array}{l}\text { Mean age/standard } \\
\text { deviation }\end{array}$ \\
\hline Lateral parieto-occipital cortex & 25 & 13 & $8 / 5$ & $20-29$ & $23.4 / 3.0$ \\
\hline $\begin{array}{l}\text { Lateral parieto-occipital cortex } \\
\text { and lateral premotor cortex }\end{array}$ & 50 and 75 & 10 & $6 / 4$ & $20-27$ & $24.8 / 3.1$ \\
\hline Inferior parietal lobule & 50 & 10 & $3 / 7$ & $22-31$ & $25.5 / 3.1$ \\
\hline Inferior parietal lobule & 75 & 16 & $9 / 7$ & $22-46$ & $25.5 / 3.5$ \\
\hline Lateral premotor cortex & 25 & 10 & $6 / 4$ & $20-27$ & $24.8 / 3.1$ \\
\hline
\end{tabular}

The time of stimulation with respect to the onset of movements is also reported. The same 10 subjects participated in premotor cortex and parieto-occipital (with TMS at $50 \%$ and $75 \%$ of $m-R T$ ) experiments.

underlying main sulci are shown in Figure 1. In each experiment, scalp locations were randomly stimulated in blocks.

\section{Pre-experimental procedures}

Before each experiment, the best point activating the right hand first dorsal interosseous muscle (FDI) was determined and the resting motor threshold (RMT) was the stimulus intensity triggering at least a $50 \mu \mathrm{V}$ response on electromyography (EMG; band pass filtering $20-2000 \mathrm{~Hz}$ ) in half of stimulations. Surface $\mathrm{Ag} / \mathrm{AgCl}$ electrodes were used (tendon-belly montage). Intensity of TMS was then set at $120 \%$ RMT. When stimulating premotor areas, the intensity of TMS was 110\% RMT to limit current diffusion to primary motor cortex. Before the experiment, stimulation points in premotor cortex were evaluated for the possibility that stimulation led to muscular responses on hand/tongue muscles by EMG. When a muscular response was evident, the point of stimulation was slightly moved anteriorly until muscular response was no longer evident. Clearly, these procedures could make the individuation of premotor cortex uncertain, but we preferred to minimize contamination from neighboring neural structures, such as the motor cortex.

\section{Experimental setting}

During experiments, each subject was seated at a table. He/she was asked to place his/her right hand on a sensor light placed $5 \mathrm{~cm}$ away from his/her chest. The sensor light was connected to an impedance detector allowing measurements of the RT (the time elapsed from the go-signal to movement onset). A metallic grid was placed over the table, covering three light emitting diodes (LEDs) positioned at the center, right, and left at about $35 \mathrm{~cm}$ from subjects. LEDs were covered by a white sheet and were visible when illuminated only. LEDs to the right and left of subjects were positioned at $40^{\circ}$ from the central one. LED lighting was the go-signal and the subject was asked to move the hand from the sensor, toward the grid to reach the LED. A cross drawn along the midline of the grid was used to maintain steady fixation during the experiment. Subject reached targets on the left and the right using peripheral vision, while the central target was reached using foveal vision. This requirement forced the inhibition of saccadic movements toward the target when it was lateral.
However, this was necessary to investigate the effect of peripheral vision in the preparation of reaching. Arm and eye movements were recorded with a digital video camera (Sony DCR-SR30E) to discard incorrect trials. Timing of TMS delivery and all events were controlled by a PCMCIA acquisition board (NI-DAQ 6024E, National Instruments, Texas, USA) allowing RT recording. Before experiments, subjects performed about 20 reaching trials with targets distributed to the center, right, and left to measure their m-RT.

At the beginning of each trial, subjects focused their attention on the cross. They maintained their right hand on the light sensor before the LED was lit. This signaled the subject to move as soon as possible, maintaining steady central fixation. Subjects performed 42 randomized trials for each stimulated point: 21 trials with and 21 without TMS (TMS and NO-TMS conditions; 14 trials for every target location, 7 with and 7 without TMS) for each point and for each TMS condition ( $25 \%, 50 \%, 75 \%$ of m-RT). If, after the execution of a block, the m-RT was reduced more than $20 \%$ (due to implicit learning or familiarization with apparatus), a new $\mathrm{m}-\mathrm{RT}$ was measured considering the last NO-TMS trials.

\section{Data treatment and statistical analysis}

TV recordings were analyzed off-line, excluding trials where eyes did not remain on the central cross for the entire trial duration. To avoid the influence of inadequate attention, trials with an RT longer than $700 \mathrm{msec}$ or shorter than $100 \mathrm{msec}$ were excluded. Trials were discarded when trajectory corrections were made. Data that were beyond two standard deviations with respect to the mean of the condition were discarded. Statistical analysis on RT was conducted with repeated measures ANOVA (see the "Results" section). A $p<0.05$ was considered as the significant threshold. When interactions among main effects were significant, further analyses were conducted to explore these effects (see the "Results" section). The normality of data was also checked.

\section{Control experiments}

Past and present experiments detected different effects due to methodological issues, also in relation to the TMS statedependent theory (Silvanto and Muggleton, 2008). Thus, we replicated part of previous experiments (see Busan et al., 2009c) 


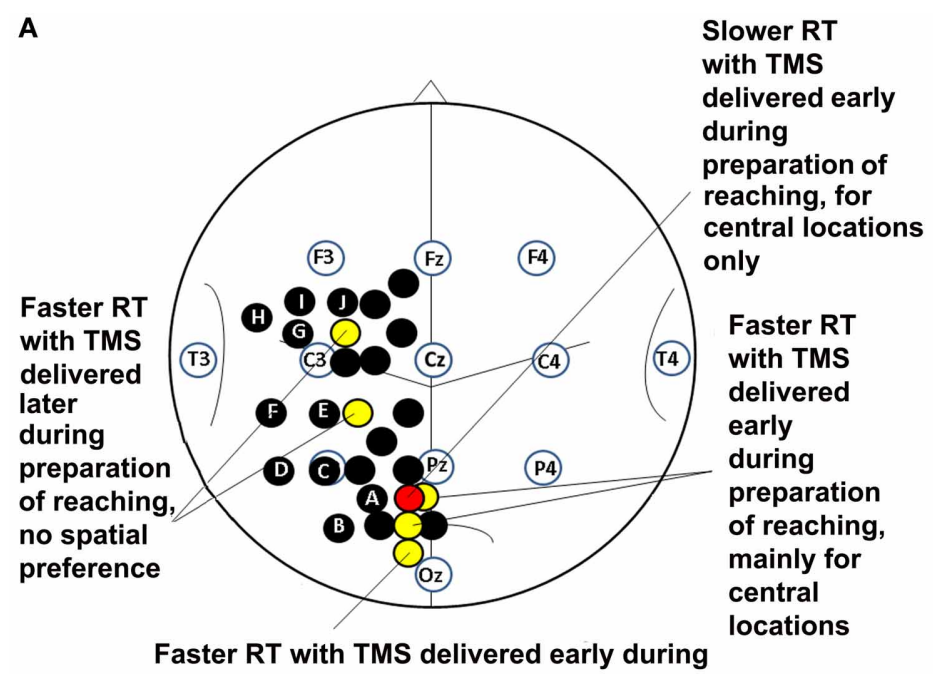

preparation of reaching, no spatial preference

B

\begin{tabular}{|c|l|}
\hline POINTS & \multicolumn{1}{|c|}{ LOCATIONS ON THE SCALP } \\
\hline A & $\begin{array}{l}8.75 \% \text { of the nasion-inion distance below Pz and } 13.75 \% \text { of the bi-auricolar } \\
\text { distance to the left from the midline }\end{array}$ \\
\hline B & $20 \%$ of the bi-auricolar distance to the left of $\mathrm{POz}$ \\
\hline C & Corresponds to P3 \\
\hline D & Corresponds to P5 \\
\hline E & Corresponds to CP3 \\
\hline F & Corresponds to CP5 \\
\hline G & $\begin{array}{l}5 \% \text { of the bi-auricolar distance to the left of } \mathrm{C} 3 \text { and } 5 \% \text { of the nasion-inion } \\
\text { distance ahead of C3 }\end{array}$ \\
\hline H & $\begin{array}{l}10 \% \text { of the bi-auricolar distance to the left of } \mathrm{C} 3 \text { and } 7.5 \% \text { of the nasion-inion } \\
\text { distance ahead of C3 }\end{array}$ \\
\hline I & $5 \%$ of the bi-auricolar distance to the left of $\mathrm{FC3}$ \\
\hline J & $5 \%$ of the bi-auricolar distance to the right of $\mathrm{FC3}$ \\
\hline
\end{tabular}

FIGURE 1 | Location of points of stimulation on the scalp and previous results. (A) Schematic drawing of the scalp showing points of stimulation in previous investigations (black, yellow and red circles; Busan et al., 2009a,c) and the present work (black circles with letters). Positions of selected scalp EEG electrodes are also reported together with an outline of main sulci. Point A corresponds to a parieto-occipital lateral position, points B-F are positioned over the putative inferior parietal lobule, while points G-J are positioned over the putative premotor cortex. (B) Table of stimulated points and related locations on the scalp. in which a slightly different setting was used. In those experiments, subjects reached a solid target: the go-signal was given with eyes closed, so as not to see the positioning of the target itself. Thus, a "double" RT was registered, composed of the time needed to open the eyes and that required to start movements. The stimulation of a region over medial SPL (5\% of the nasioninion distance below $\mathrm{Pz}$ and 5\% of the bi-auricular distance to the left) was effective in increasing RT at $75 \%$ of the (double) m-RT.

In eight right-handed, healthy subjects (three males, five females; age range $20-25$, mean age 22.4 , standard deviation SD- 1.5), we performed the same experiment as the previous by applying TMS at $75 \%$ of m-RT of the (double) RT over medial SPL.

Results were compared to those collected in a second control experiment, where six right-handed, healthy subjects (two males, four females; age range 22-29; mean age 23.7, SD 2.7) performed the same task, but with open eyes and using LEDs instead of the solid target. TMS was applied at 50\% of m-RT, a time considered as equivalent to the $75 \%$ of the (double) m-RT in previous experiments. Statistical comparisons were made using Student's $t$-test. The results obtained from these settings have been qualitatively compared to evaluate the possibility that different effects could be observed with respect to slightly different experimental requests, possibly sustaining the TMS state-dependent theory (Silvanto and Muggleton, 2008).

\section{TMS/EEG study}

A TMS/EEG experiment was carried out to confirm and extend previous findings (Zanon et al., 2010). Nine right-handed healthy subjects (five males and four females, age range 20-26 years, mean age 23.9 years, SD 2.1) participated in these experiments. Subjects were seated with closed eyes for the duration of blocks to reduce ocular artifacts.

TMS apparatus, coil orientation, protocols, instrumentations and data acquisition procedures were the same as those described in Zanon et al. (2010). Stimuli were delivered on the left parietal 
cortex on the same scalp location stimulated previously (Zanon et al., 2010). It corresponded to a region putatively involved in reaching preparation (Busan et al., 2009a).

\section{EEG and data analysis}

EEG traces were recorded and treated as in Zanon et al. (2010). For data analysis, an average of 95.7 (SD 15.3) epochs was considered for real TMS and 89.7 (SD 15.3) for sham. Part of the TMS artifact as well as all the other remaining artifacts were eliminated as much as possible using EEGLAB (Delorme and Makeig, 2004). The first $20 \mathrm{msec}$ prior to the delivery of stimulations and $35 \mathrm{msec}$ after them were deleted. Independent component analysis (Jung et al., 2000) allowed for elimination of artifacts (e.g., those related to the slow decay/recovery after TMS).

Epochs were then averaged to obtain real and sham TMS evoked potentials (TEPs). Considering the remaining TMS artifact that could influence the analyses, a "linear detrend" function was applied when needed, generally in a time between 35 and $300 \mathrm{msec}$ after the delivery of stimuli. Finally, averaged real and sham TEPs were re-referenced (average reference).

sLORETA (standardized low resolution brain electromagnetic tomography; Pascual-Marqui, 2002) was used to compute the cortical three-dimensional distribution of neuronal activity comparing real and sham TEPs. sLORETA is a standardized discrete, three-dimensional distributed, linear, minimum norm inverse solution (Pascual-Marqui, 2002). Computations were made in a realistic head model (Fuchs et al., 2002) using the MNI152 template (Mazziotta et al., 2001), with three-dimensional space solution restricted to cortical gray matter, as determined by the probabilistic Talairach atlas (Lancaster et al., 2000), and with electrode positions superimposed on the MNI152 scalp (Oostenveld and Praamstra, 2001; Jurcak et al., 2007). The intracerebral volume is partitioned in 6239 voxels at $5 \mathrm{~mm}$ spatial resolution. Anatomical labels such as Brodmann areas are also reported using MNI space, with corrections to Talairach space (Brett et al., 2002).

In the present work, sLORETA was used to perform a voxel-byvoxel within-subjects comparison of real vs. sham TMS induced current density distribution in the brain. Significant differences in EEG source maps were assessed with non-parametric statistical analysis (Statistical non-Parametric Mapping: SnPM; Nichols and Holmes, 2002), as previously described (Zanon et al., 2010).

We reduced the localization error by applying regularization in the source reconstruction. We considered the mean signal-tonoise ratio of averaged ERPs, for each subject in every condition, from 35 to $300 \mathrm{msec}$ after delivery of the stimulus with respect to baseline.

After reconstructing the EEG cortical sources distribution for both real and sham TMS conditions, analyses were conducted considering single time frames in a time ranging from 35 to $300 \mathrm{msec}$ after stimulation. Statistics were implemented also considering the mean neural activity in time windows individuated by visual inspection of TEPs. The following comparisons were implemented: from 35 to $60 \mathrm{msec}$, from 60 to $130 \mathrm{msec}$, from 130 to $245 \mathrm{msec}$, and from 245 to $300 \mathrm{msec}$. Significance was set at $p<0.05$, correcting for multiple comparisons. SnPM in sLORETA allowed for correction of multiple comparisons even with respect to all voxels and all time samples.

\section{RESULTS \\ BEHAVIORAL TMS STUDY}

We considered the main effects and interactions among TMS (yes/no), location of stimulation on the scalp (one, four, or five positions), target position in space (central, left, and right) with repeated measures ANOVA. We conducted analyses for each timing of TMS delivery. Student's $t$-test (Bonferroni corrected) was used to characterize significant findings. When a three-way interaction was significant, the statistical model was investigated by two-way interactions and then with a Student's t-test (Bonferroni corrected). Results obtained for all conditions (Figure 1) are summarized in Table 2. We observed that an effect related to target position was always evident (parieto-occipital cortex: $25 \% \mathrm{~m}-$ RT: $p=0.043 ; 50 \%$ m-RT: $p=0.012 ; 75 \%$ m-RT: $p=0.013$; parietal cortex: always $p<0.009$; premotor cortex: always $p<$ 0.009 ), mainly indicating that subjects had longer RTs for movements toward the left targets. Moreover, TMS always resulted in faster RT when stimulating at 25\% of m-RT (TMS main factor, independently of target position, always $p<0.009$ ).

When considering the premotor cortex, we observed an interaction of TMS vs. location of stimulation at $25 \%$ of m-RT ( $p=$ $0.004)$. However, subsequent analyses showed the presence of significant effects on all stimulated points (point G: $p<0.009$; point $\mathrm{H}: p<0.009$; point I: $p<0.009$; point $\mathrm{J}: p<0.009$ in Figure 1). Due to the wide distribution of effective points of stimulation, we considered these results as unspecific effects, likely confirming that the facilitating effect caused by TMS when stimulating at $25 \%$ of m-RT was not related to a genuine effect (e.g., Sawaki et al., 1999). All remaining comparisons never reached significance.

\section{CONTROL EXPERIMENTS}

Two control experiments were performed. In the first, we replicated the original result of slowed RT (TMS mean reaction time: 690.25, SD 101.5; no-TMS mean reaction time: 652.8, SD 109.2; $p=0.04$ ) when stimulating medial left posterior parietal cortex using the original experimental setting (Busan et al., 2009c), reaching toward the center. We performed a second experiment where subjects were required to keep their eyes open. In this instance we did not replicate findings of the previous experiment, and no significant differences were evident between TMS and noTMS when reaching toward the center with foveal observation (TMS mean reaction time: 309.0, SD 33.8; no-TMS mean reaction time: 312.1 , SD 30.0; $p=0.60)$.

\section{TMS/EEG STUDY \\ ERP description and sLORETA}

Real and sham TEPs showed positive and negative deflections (see, for example, Paus et al., 2001; Bonato et al., 2006). Specifically, when $\mathrm{Cz}$ electrode was considered, we observed four peaks (Figure 2) during real TMS: (i) a negative component (N45; mean amplitude -4.2 microvolts, SD 3.0 ; mean latency $44.8 \mathrm{msec}$, SD 2.4), (ii) a positive one (P65; mean amplitude 1.7 microvolts, SD 1.5; mean latency $63.2 \mathrm{msec}$, SD 5.2), followed by (iii) a negative one (N95; mean amplitude -6.6 microvolts, SD 2.1; mean latency $95.5 \mathrm{msec}, \mathrm{SD} 11.7$ ), and, finally, (iv) a positive one (P165; mean amplitude 7.2 microvolts, SD 2.3; mean 
Table 2 | Reaction times observed in behavioral experiments.

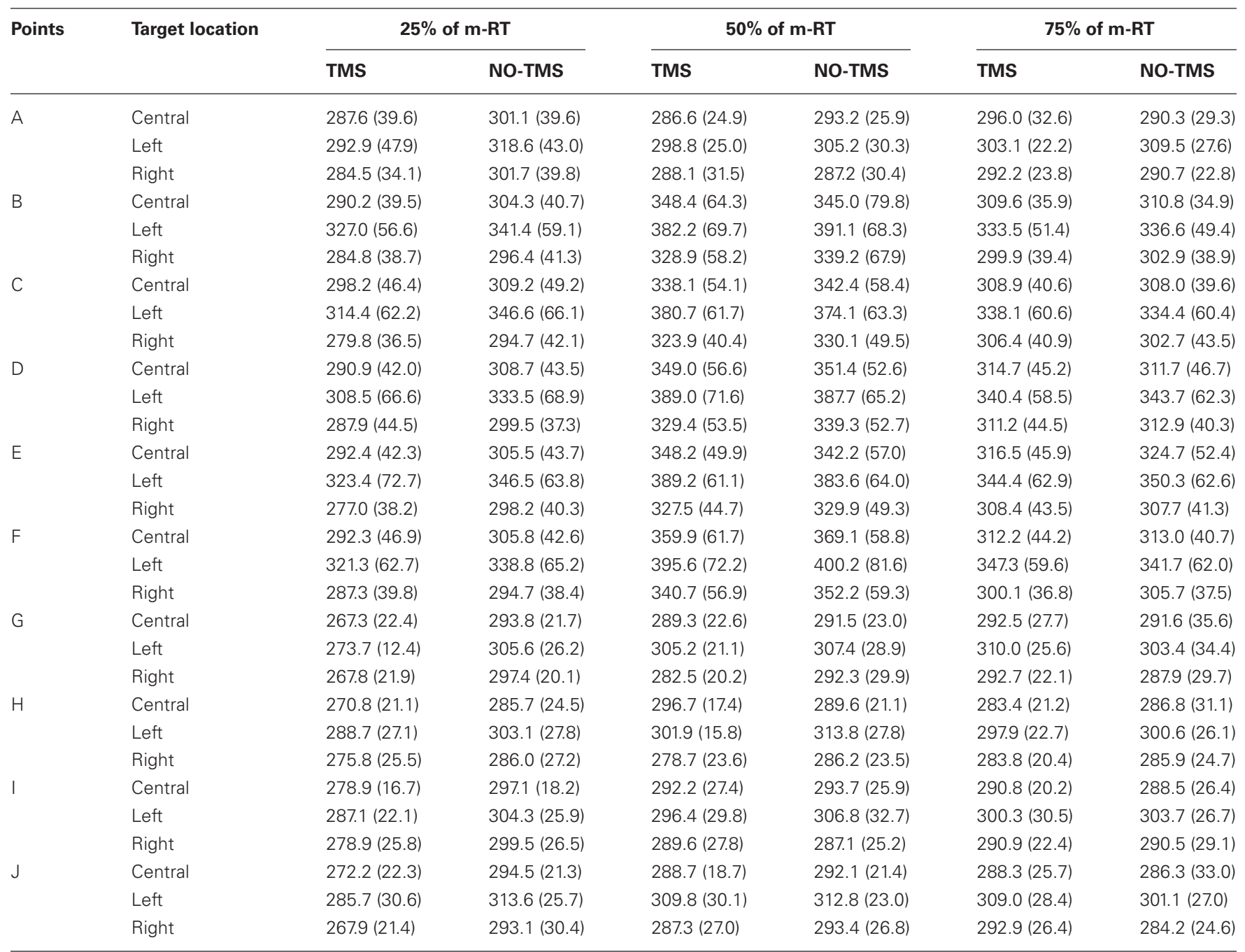

Mean of reaction times (SD in brackets) obtained for parieto-occipital (point A), parietal (points B-F), and premotor (points G-J) cortices.

latency $161.9 \mathrm{msec}$, SD 15.3). Sham TEPs showed similar deflections with reduced amplitudes compared to real TMS (Figure 2). The acoustic contamination was evident (Nikouline et al., 1999) in both conditions.

Time frame by time frame comparison of the entire time window showed a significant $(p<0.05)$ difference between the real and sham TMS in the time ranges between 116-126 msec, 134-146 msec, and at about $190 \mathrm{msec}$ after the delivery of stimuli.

In the first time range (116-126 msec), we observed significant voxels in the left postcentral gyrus, left inferior parietal lobule (IPL), and right motor regions. In the same interval, but with a slight delay, further significant voxels were also evident in the right cuneus, right middle occipital gyrus, right lingual gyrus, right precuneus, right SPL, right IPL, as well as in the right angular gyrus. The cingulate gyrus and the posterior cingulate also showed significant voxels in this time window.

In the second time range $(134-146 \mathrm{msec})$ we observed significant voxels in the right SPL, right IPL, right supramarginal gyrus, right postcentral gyrus, precuneus and sub-gyral. Finally, at 190 msec after TMS we observed significant voxels in the left superior temporal gyrus and supramarginal gyrus.

Maximal peaks of activation and number of voxels activated for each significant time frame are reported in Table 3. The main patterns of activations are shown in Figure 3.

We also took into consideration the mean activation across the overall four time-windows of interest (Figure 4). In this case, significance was $p<0.0125$. The first time window (from 35 to $60 \mathrm{msec}$ ) did not reach the threshold for significance, while it was reached in the second time window $(60-130 \mathrm{msec})$ : we observed significant voxels in the contralateral posterior regions (mainly in the cuneus and precuneus -bilaterally-, IPL and SPL, the middle occipital gyrus, the lingual gyrus -bilaterally-, the cingulate gyrus, and posterior cingulate -bilaterally). Significant voxels were also evident in the right inferior, middle, and superior temporal gyrus. Finally, we observed significant voxels in the left and right superior, middle and medial frontal gyrus, right inferior frontal gyrus, left and right precentral gyrus, right postcentral gyrus, and left sub-gyral. 


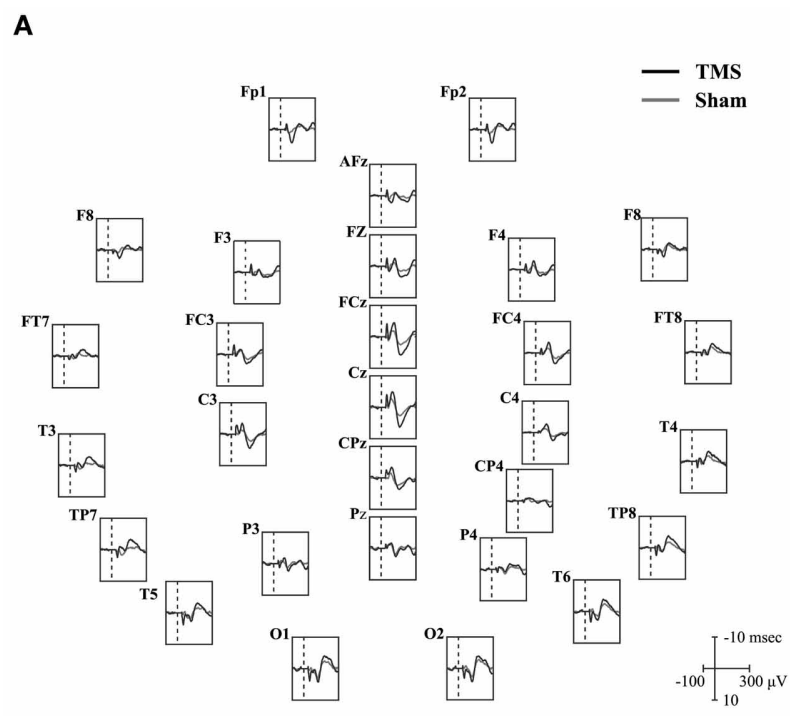

B

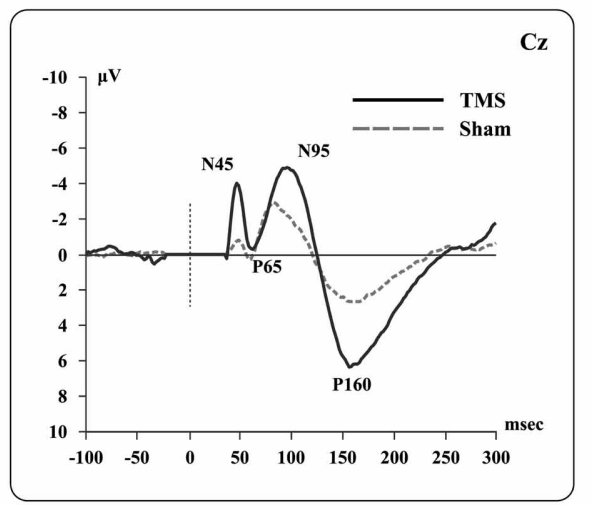

FIGURE 2 | Real TMS and sham TMS evoked potentials in 9 healthy subjects. (A) Grand-average of real TMS evoked potentials ranging from $100 \mathrm{msec}$ before to $300 \mathrm{msec}$ after the stimulation, showing all recorded electrodes. Real TMS evoked potentials are superimposed on sham-evoked potentials. Site of stimulation over the parietal cortex is also shown. (B) Grand-average of evoked potentials recorded at the $\mathrm{Cz}$ electrode, showing the main deflections described in the text.

The third time window (130-245 msec) showed a pattern of significant voxels that comprised the right precentral and postcentral gyrus, right inferior frontal gyrus, and the left medial frontal gyrus. Posteriorly, we observed significant voxels in the right and left fusiform gyrus, left uncus, left and right parahippocampal gyrus, right cuneus and precuneus, right posterior cingulate, right lingual gyrus and right IPL. Finally, significant propagation was seen also in the left and right inferior temporal gyrus and the right insula.

The last window, ranging from 245 to $300 \mathrm{msec}$, showed activations in the right postcentral gyrus and left superior temporal gyrus. Results are summarized in Table 4 and Figure 4.

\section{DISCUSSION}

In the present investigation, we report findings obtained by stimulating cortical areas along a "dorso-lateral" stream in the left hemisphere in healthy right-handed people during the preparation of visually-guided reaching movements performed with the dominant hand. Lateral parietal and premotor regions resulted not to be strictly involved in the preparation of visually-guided reaching as measured by the present protocol. This confirms that the neural network for preparation of reaching is quite localized, as already suggested by our previous works (Busan et al., 2009a,c).

The following discussion will focus on the parietal cortex, considering that our previous results on dorsal premotor cortex (Busan et al., 2009a) could be related to non-specific effects, even if we are well aware that the premotor cortex plays a role in the preparation of motor responses and in reaching (e.g., Prado et al., 2005; Pesaran et al., 2006; Batista et al., 2007; Hoshi and Tanji, 2007; Beurze et al., 2010).

\section{SEGREGATED SYSTEMS FOR THE PREPARATION OF REACHING MOVEMENTS?}

The present findings suggest that the neural network herein stimulated is not strongly involved in visually-guided reaching movements. Our previous studies (Busan et al., 2009a,c) showed the presence of a discrete dorsal neural circuit starting from the medial parieto-occipital cortex, involving the SPL near the intraparietal sulcus and the dorsal premotor cortex. However it should be kept in mind that the effect of TMS could be due to the modulation of regions simply linked to the stimulated area.

The left hemisphere was chosen for its dominance for praxis (e.g., Goodale, 1988; Haaland and Harrington, 1989), and the left parietal cortex involvement in arm movement planning (Rushworth et al., 2003; Wheaton et al., 2009). SPL lesions in the left hemisphere can result in misreaching throughout the workspace (Perenin and Vighetto, 1988), while a right hemisphere lesion may be more related with lateralized visual field effects (Perenin and Vighetto, 1988; Battaglia-Mayer et al., 2006). However, left parietal lesions may have effects only in the contralateral visual field (Riddoch, 1935). Thus, the posterior parietal cortex plays a pivotal role in the preparation of actions (Goodale and Milner, 1992; Jeannerod et al., 1995; Andersen et al., 1997) with a contralateral limb bias in more anterior parietal regions and less evident in the parieto-occipital cortex (Busan et al., 2009b; Vesia et al., 2010).

Our previous and present results are in agreement with literature (e.g., Kastner et al., 1998; Fattori et al., 2001, 2005; Andersen and Buneo, 2002; Calton et al., 2002; Snyder et al., 2006; Trillenberg et al., 2007; Ciavarro and Ambrosini, 2011; Striemer et al., 2011) supporting a role for SPL in preparation of reaching (Goodale and Milner, 2004; Buneo and Andersen, 2006). In particular, Beurze et al. (2010) found parieto-occipital activations related with foveal vision comparable with our results.

Striemer et al. (2011) suggested that SPL is preferentially related to programming of actions and on-line control, while IPL should not. The latter should be more related with selecting the goal and/or target of the action. They found an effect on endpoint accuracy when using a triple pulse TMS over SPL during the preparation of movement, while this was not observed when stimulating IPL. They also observed a significant reduction in RT, which might be related to unspecific effects but it might also be a genuine result. In fact, this finding is congruent with 
Table 3 | Results from time frame by time frame sLORETA analysis.

\begin{tabular}{|c|c|c|c|c|c|}
\hline $\begin{array}{l}\text { Time of activation } \\
\text { (msec) }\end{array}$ & \multicolumn{3}{|c|}{ Maximal peak of activation } & $\begin{array}{l}\text { Other significant } \\
\text { voxels (BA) }\end{array}$ & $\begin{array}{l}\text { Number of } \\
\text { activated } \\
\text { voxels }\end{array}$ \\
\hline 116 & $-50,-30,55$ & 2 & Left postcentral gyrus & $40 \mathrm{~L}, 1 \mathrm{~L}, 4 \mathrm{R}$ & 15 \\
\hline 118 & $-45, \quad 25,50$ & 2 & Left postcentral gyrus & $1 \mathrm{~L}, 3 \mathrm{~L}, 19 \mathrm{R}$ & 10 \\
\hline 120 & $40,-75,40$ & 19 & Right Precuneus & $2 \mathrm{~L}, 3 \mathrm{~L}, 7 \mathrm{R}, 18 \mathrm{R}, 30 \mathrm{R}, 31 \mathrm{R}, 39 \mathrm{R}, 40 \mathrm{~L} / \mathrm{R}$ & 57 \\
\hline 124 & $-5,-15,30$ & 23 & Left cingulate gyrus & $17 \mathrm{R}, 18 \mathrm{R}, 19 \mathrm{R}, 23 \mathrm{R}, 24 \mathrm{~L}, 29 \mathrm{R}, 30 \mathrm{R}, 31 \mathrm{~L} / \mathrm{R}$ & 111 \\
\hline 126 & $10,-75,15$ & 18 & Right cuneus & $7 \mathrm{R}, 17 \mathrm{R}, 23 \mathrm{R}, 30 \mathrm{R}, 31 \mathrm{R}$ & 109 \\
\hline 134 & $20,-60,55$ & 7 & Right precuneus & l & 11 \\
\hline 136 & $25,-60,60$ & 7 & Right superior parietal lobule & $5 \mathrm{R}$ & 42 \\
\hline 138 & $30,-60,60$ & 7 & Right superior parietal lobule & $5 \mathrm{R}, 40 \mathrm{R}$ & 27 \\
\hline 140 & $30,-55,60$ & 7 & Right superior parietal lobule & $2 R, 5 R, 40 R$ & 44 \\
\hline 190 & $-60,-60,20$ & 22 & Left superior temporal gyrus & $40 \mathrm{~L}$ & 2 \\
\hline
\end{tabular}

Time of activation and location of maximal peaks which were significant with analysis made on the entire window of interest (35-300 msec). The remaining significant voxels are also reported. BA: Brodmann Areas; $L=$ left; $R=$ right.

our previous results (Busan et al., 2009a,c). Striemer et al. (2011) suggested that those results might be correlated to attentional or intentional processes rather than to motor planning. Along these lines, we already controlled the possibility that unspecific attention processes biased our results (Busan et al., 2009a,c), but the possibility that they were also related to attention processes specifically related to reaching movements cannot be ruled out. However, these processes should be more likely related with IPL than with SPL involvement (Rushworth et al., 2001; Desmurget and Sirigu, 2009). Striemer et al. (2011) also suggested that an influence of TMS on motor programming should have an impact on motor performance in terms of movement accuracy, while an influence on motor attention or intention (Desmurget and Sirigu, 2009) should affect RT (Striemer et al., 2009). However, Snyder et al. (2006) demonstrated in nonhuman primates that RT could be affected when interfering with SPL. Other studies suggested that IPL may also have a role in programming goal directed reaching, whereas the SPL and intraparietal sulcus may be more related to on-line control of movement (Glover, 2004; Pisella et al., 2006).

Thus, our present and previous data (Busan et al., 2009a,c) support the existence of different and partially segregated neural circuits for the implementation of different motor tasks (Jeannerod et al., 1995). They are consistent with the suggestion of a "dorso-medial" stream preferentially involved in reaching movements, classically opposed to a "dorso-lateral" stream that preferably manages reach-to-grasp and/or grasping movements (e.g., Jeannerod et al., 1995; Burnod et al., 1999; Randerath et al., 2010). This suggestion is supported by results obtained with different paradigms and settings (Desmurget et al., 2005; Prado et al., 2005; Fernandez-Ruiz et al., 2007; Filimon et al., 2009; for a review see Vesia et al., 2010).

However, evidence against this possibility has also been advanced (Desmurget et al., 1996; Smeets and Brenner, 1999;
Mon-Williams and McIntosh, 2000), showing that the implementation of reaching is not so much segregated, and that wider circuits can participate. In fact, circuits for preparation of reaching may overlap with the neural requests needed for grasping or reach-to-grasp implementation, with still more integrated mechanisms needed for prehension (Binkofski et al., 1998; Smeets and Brenner, 1999; Ulloa and Bullock, 2003; Tunik et al., 2005; Rice et al., 2006). Moreover, it should be noted that regions of the IPL, as for example the angular or the supramarginal gyrus, have been associated with preparation and/or on-line control of visually guided reaching (Koch et al., 2008; Vesia et al., 2008, 2010; Reichenbach et al., 2011).

In the brain, information can be processed serially as well as along parallel pathways (e.g., Burnod et al., 1999; Naranjo et al., 2007; Buneo et al., 2008). Serial organization fits well with the concept that information travels from peripheral to complex "association" areas and then to output channels for action. Similarly, parallel organization of cognitive processes (Cisek and Kalaska, 2010) is supported by a series of studies suggesting that tasks such as visuo-motor integration rely on a network that provides concomitant activation of different cortical regions (Battaglia-Mayer et al., 2006; Naranjo et al., 2007). Our previous data (Busan et al., 2009a,c) support the vision of a mainly serial elaboration of information in this type of task, but also offer a suggestion toward the concept of a parallel elaboration.

TMS/EEG results are in relation with state-dependent activity of the brain, since they were obtained in a resting condition and closed eyes. Brain dynamics were evaluated in a basic condition, usually defined as a "default mode brain state" (Raichle et al., 2001; Raichle and Snyder, 2007; Greicius et al., 2009) where the brain is however active. This reduced the possibility of EEG contamination by movements or other processes. 


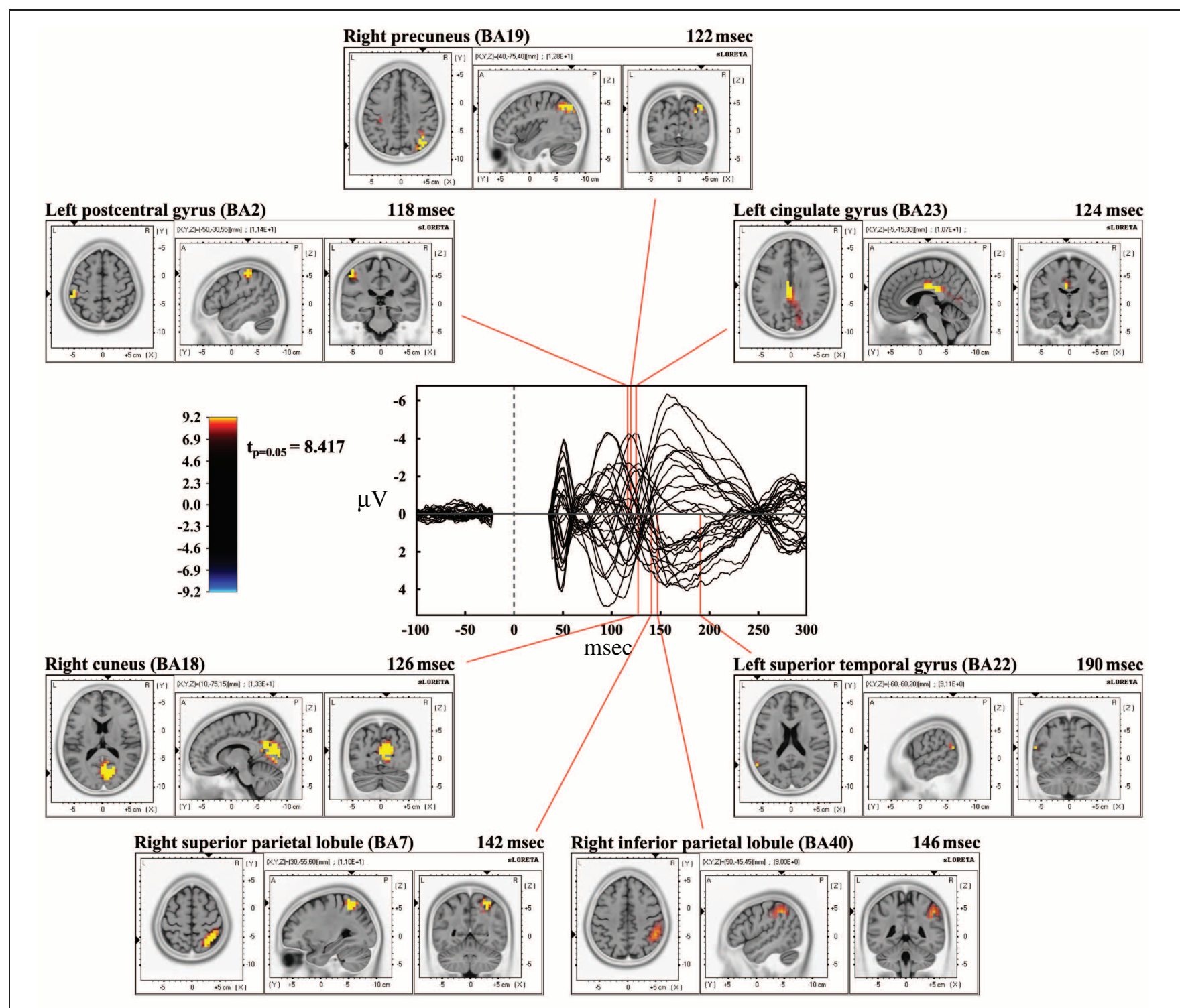

FIGURE 3 | Results from time frame by time frame sLORETA analysis. Representation of the main patterns of activation obtained in time frame by time frame analysis compared to a butterfly plot showing the grand-averaged (for all subjects) evoked potentials (real TMS) for each electrode.

Concurrent TMS/EEG offers insights into how brain areas interact during information processing (Ilmoniemi and Kicić, 2010). The present work shows propagation of activity ranged mainly from the left somatosensory and parietal structures to right parietal, somatosensory, motor, and more posterior activations. Deep regions of the brain, such as cingulate regions, had significant voxels in late and discrete time windows. Finally, activity in the left temporal and parietal cortices was evident around $190 \mathrm{msec}$ from the delivery of TMS. Instead, when considering the mean neural activity in discrete time of interest, interactions were found among the parietal cortex and, mainly, the posterior regions of the brain. Moreover, significant propagations were found in the left and right frontal regions and in post-central areas, as well as in occipito-temporal regions, and in the right insula.
Our previous studies (Zanon et al., 2010) suggested the presence of an interchange of information between parietal cortex and occipito-temporal cortex at about $170 \mathrm{msec}$ after TMS. An interaction between dorsal and ventral streams has already been proposed (e.g., Himmelbach and Karnath, 2005; Borra et al., 2008; Makuuchi et al., 2012). Valyear and Culham (2010) showed that tool-selective activity was related with parietal and ventral stream activations.

Interestingly, in the present findings, we observed the activation of a neural source around $190 \mathrm{msec}$ from TMS (stimulating the left parietal cortex) in a ventral region in left temporo-parietal cortex. This gives further support to previous results regarding the possibility of an interchange of information between the dorsal and ventral streams: this region has been reported to have a supportive role in the elaboration, for 


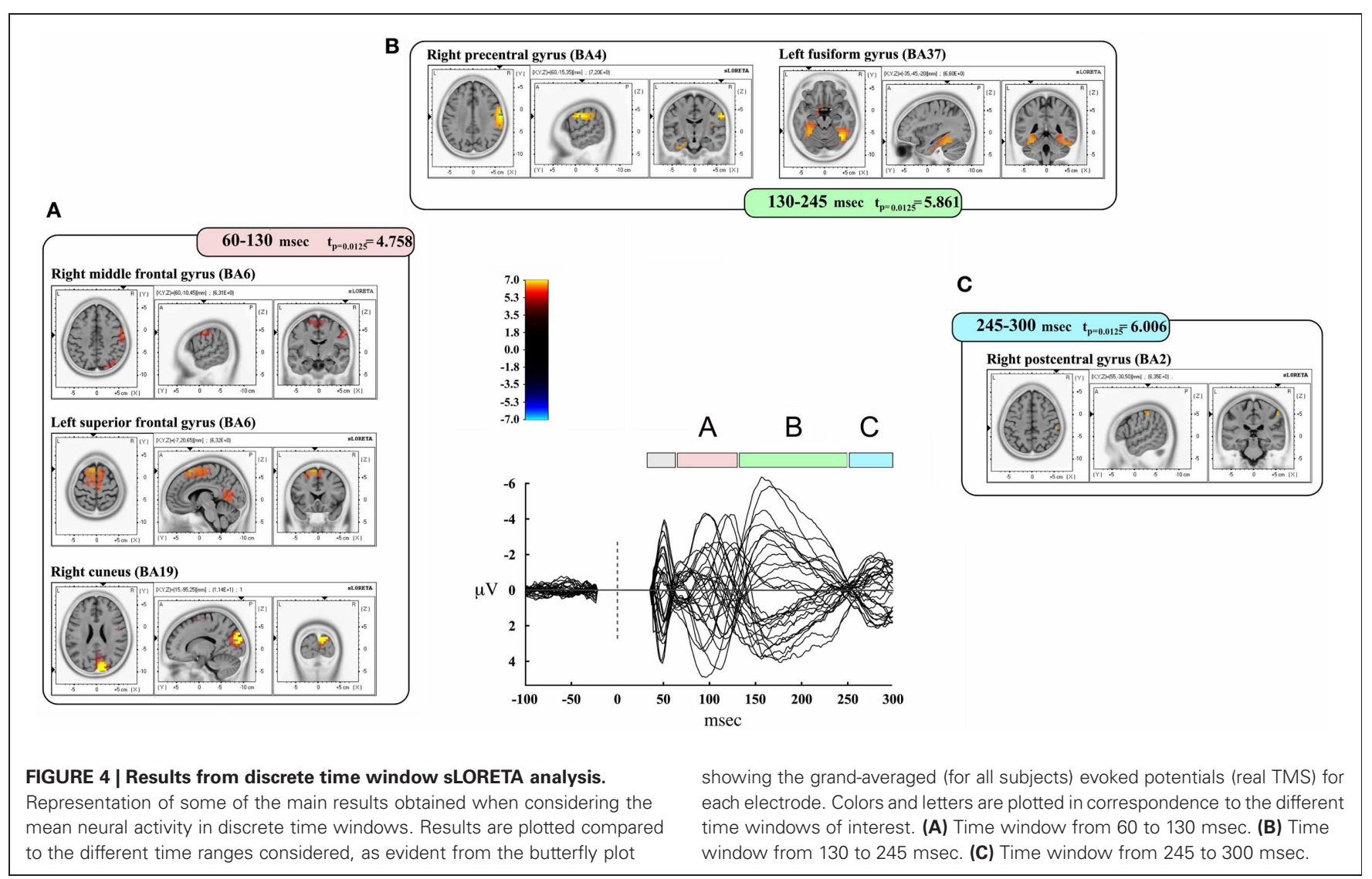

Table 4 | Results from discrete time windows sLORETA analysis.

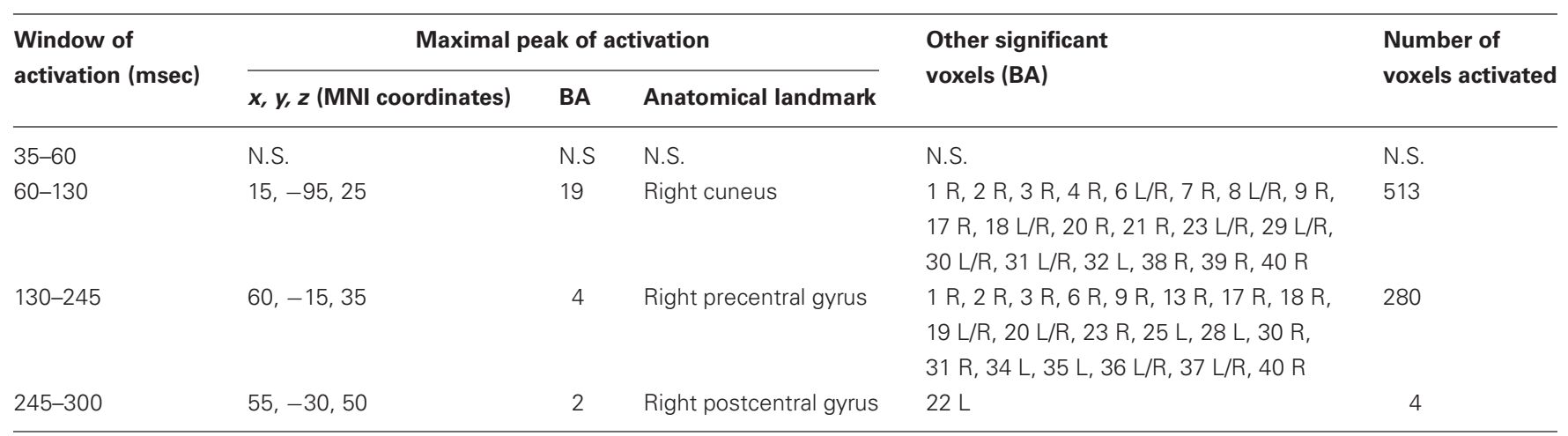

Time of activation and location of maximal peaks which were significant are reported. The remaining significant voxels are also reported. BA: Brodmann Areas; $L$, left; R, right; N.S. = Not Significant.

example, of object features in a cross-modal integration (Taylor et al., 2009). Moreover, the analysis of mean neural activity confirmed the presence of neural activations in occipito-temporal regions of the brain in a time window comprised between 130-245 msec, again suggesting interactions between the two systems.

The present findings are in general agreement with previous TMS/EEG studies that assessed the temporal dynamics underlying different tasks. For example, Massimini et al. (2005) investigated how the activation of cortical areas was transmitted to the rest of the brain during wakefulness or sleep. In the case of aware subjects, activation in the parietal cortex was observed about $120 \mathrm{msec}$ after TMS onset. An inverse propagation from the parietal cortex to premotor regions in comparable times was also observed. Another study showed that stimulation of left posterior regions of the brain could elicit activations of frontal areas bilaterally in the first $80 \mathrm{msec}$ from the delivery of the stimulus, depending on a series of variables such as, for 
example, stimulation intensity or stimulation angle (Casali et al., 2010).

The present findings integrate and extend previous results (Zanon et al., 2010), suggesting the possibility of the existence of wide links between the parietal cortex and other brain regions, ranging from frontal to more posterior parietal, temporal and occipital areas (e.g., Hagmann et al., 2008; Borra and Rockland, 2011). These findings are the result of a series of possible direct and/or indirect links among the highlighted cortical regions. The ones discussed are only the main aspects related to the present pattern of cortico-cortical interactions centered on the parietal cortex, in order to guide the interpretation of behavioral results. Further information about this topic can be found by referring to more specific publications (e.g., Hagmann et al., 2008; Mars et al., 2011).

\section{PREPARATION AND INHIBITION OF MOVEMENTS}

This study shed light on the neural underpinnings of visuallyguided reaching movements. The knowledge of regions involved in reaching movement preparation is relevant also to understand the way in which the suppression of reaches is implemented. To this respect it has been proposed that a network composed by the inferior frontal cortex, the subthalamic nucleus and pre-SMA (supplementary motor area) is responsible of inhibitory control (Aron et al., 2007a). In fact, neural substrates of suppression have been found in SMA, pre-SMA, basal ganglia and frontal regions (e.g., Matsuzaka and Tanji, 1996; Aron and Poldrack, 2006; Chen et al., 2010; Mirabella et al., 2012; Swann et al., 2012), as well as in cingulate cortex, insula, prefrontal, fronto-parietal and temporal regions (e.g., Kalaska and Crammond, 1995; Aron et al., 2007b; Chikazoe et al., 2009; Coxon et al., 2009; Stinear et al., 2009; Swick et al., 2011). However, evidence suggests that the motor cortex should be the final target of inhibitory commands that could be elaborated elsewhere (Coxon et al., 2006; Mirabella et al., 2011). Furthermore it has been shown that the parietal cortex can play a role in response stopping or inhibition (e.g., Watanabe et al., 2002; Coxon et al., 2009; Wheaton et al., 2009) and in movement decision-related tasks (Karch et al., 2009). Again these are structures that might also be involved in movement control (e.g., Battaglia-Mayer et al., 2006, 2007; Lindner et al., 2010; Ciavarro and Ambrosini, 2011). Some overlap between inhibition and execution of reaching is witnessed by the fact that strategic changes in movement programming for the very same movements under different cognitive contexts have been shown, requiring different degrees of control during movement (Mirabella et al., 2008). However, Mirabella et al. (2006) showed that the Stop/Go processes interacting in a countermanding task are independent, but likely influenced by a common factor when they are under the control of the same hemisphere.

\section{LIMITATIONS OF THE STUDY}

The present study has a few limitations. The use of slightly different experimental settings could lead to poorly comparable results. However, the lack of significant effects cannot be entirely attributed to the differences adopted. Particular time windows of stimulation or the state-dependent excitability of the cortex could be also critical. Finally, the possibility that different regions could intervene in different manner compared to task requests should be kept in mind.

One of the changes we adopted in the present experiments was to make the subject work with open rather than closed eyes. The rationale for using a "double" RT paradigm in the previous experiments (putatively, a first one from the go signal to the opening of the eyes and a second one from the opening of the eyes to the start of movement; Busan et al., 2009a,b,c) was in relation with the possibility to study a real-time preparation of reaching movements, avoiding that the subject knew in advance positioning of the target. However, it is evident that the presence of a "double" RT represents a complication. On the other hand, in the present experimental setting, a possible effect related to the visual feedback of the arm cannot be completely ruled out. However, in our previous study (Busan et al., 2009c), the evidence of a slower RT only toward the central reaching position could make this point less critical (e.g., Ferraina et al., 1997; Graziano et al., 2000; Buneo and Andersen, 2006; Khan et al., 2007; Filimon et al., 2009; Beurze et al., 2010; Bosco et al., 2010). We should also consider the possibility that different preparations of movement could be present at the same moment in the brain (Cisek and Kalaska, 2010; Cui and Andersen, 2011) before the go-signal, and that subjects simply selected the movement when requested (Cisek and Kalaska, 2010).

We might have not been able to apply TMS at the right time and the possibility that some effects were undetected in present and previous investigations remains, also in relation to the state-dependent theory (Silvanto and Muggleton, 2008). In this sense, the facilitating effects induced by TMS could be also explained as a possible disruption of inhibitory/ controlling/competitive processes, which allowed the controlled areas to enhance their functioning (Walsh and Pascual-Leone, 2003).

Specific limitations in the TMS/EEG experiment may also be present. For example, TMS evokes not only responses related to TMS, but also potentials due to acoustic and somatic stimulation. Sham stimulation was implemented to obtain a control for acoustic stimulation, but an optimal control for somatic stimulation is difficult to be obtained. Even if we tried to eliminate the majority of artifacts with ICA (Jung et al., 2000), the possibility remains that these and some other hidden artifacts were still present in the collected data.

\section{CONCLUDING REMARKS}

The data herein reported contribute to further understand the organization of movements. They are in agreement with the suggestion that SPL is more involved in the preparation of natural reaching compared to more lateral structures. However, TMS/EEG findings showed that parietal cortex stimulation propagates toward a wide system of areas. This suggests that segregation among neural systems is not restrictive, and favors alternative hypotheses suggesting that overlap between different neural structures is needed for the implementation of different movements.

This evidence also represents a complementary point of view with respect to neural organization of movement and response 
inhibition or stopping, suppression of pending actions, or the quick change of prepared actions. In fact, the organization of reaching and its neural machinery should be highlighted in order to relate them to situations such as inhibition or stopping of action.

\section{REFERENCES}

Andersen, R. A., and Buneo, C. A. (2002). Intentional maps in posterior parietal cortex. Annu. Rev. Neurosci. 25, 189-220.

Andersen, R. A., and Cui, H. (2009). Intention, action planning and decision making in parietal-frontal circuits. Neuron 63, 568-583.

Andersen, R. A., Snyder, L. H., Bradley, D. C., and Xing, J. (1997). Multimodal representation of space in the posterior parietal cortex and its use in planning movements. Ann. Rev. Neurosci. 20, 303-330.

Aron, A. R., Behrens, T. E., Smith, S., Frank, M. J., and Poldrack, R. A. (2007a). Triangulating a cognitive control network using diffusionweighted magnetic resonance imaging (MRI) and functional MRI. J. Neurosci. 27, 3743-3752.

Aron, A. R., Durston, S., Eagle, D. M., Logan, G. D., Stinear, C. M., and Stuphorn, V. (2007b). Converging evidence for a fronto-basal-ganglia network for inhibitory control of action and cognition. J. Neurosci. 27, 11860-11864.

Aron, A. R., and Poldrack, R. A. (2006). Cortical and subcortical contributions to stop signal response inhibition: role of the subthalamic nucleus. J. Neurosci. 26, 2424-2433.

Bakola, S., Gamberini, M., Passarelli, L., Fattori, P., and Galletti, C. (2010). Cortical connections of parietal field PEc in the macaque: linking vision and somatic sensation for the control of limb action. Cereb. Cortex 20, 2592-2604.

Batista, A. P., Santhanam, G., Yu, B. M., Ryu, S. I., Afsheen, A., and Shenoy, K. V. (2007). Reference frames for reach planning in macaque dorsal premotor cortex. J. Neurophysiol. 98, 966-983.

Battaglia-Mayer, A., Archambault, P. S., and Caminiti, R. (2006). The cortical network for eye-hand coordination and its relevance to understanding motor disorders of parietal patients. Neuropsychologia 47, 2607-2620.

Battaglia-Mayer, A., Mascaro, M., and Caminiti, R. (2007). Temporal evolution and strenght of neural activity in parietal cortex during eye and hand movements. Cereb. Cortex 17, 1350-1363.
Beurze, S. M., Toni, I., Pisella, L., and Medendorp, W. P. (2010). Parietofrontal cortex reference frames for reach planning in human. J. Neurophysiol. 104, 1736-1745.

Binkofski, F., Dohle, C., Posse, S., Stephan, K. M., Hefter, H., Seitz, R. J., and Freund, H. J. (1998). Human anterior intraparietal area subserves prehension: a combined lesion and functional MRI activation study. Neurology 50, 1253-1259.

Bonato, C., Miniussi, C., and Rossini, P. M. (2006). Transcranial magnetic stimulation and cortical evoked potentials: a TMS/EEG co-registration study. Clin. Neurophysiol. 117, 1699-1707.

Borra, E., Belmalih, A., Calzavara, R., Gerbella, M., Murata, A., Rozzi, S., and Luppino, G. (2008). Cortical connections of the macaque anterior intraparietal (AIP) area. Cereb. Cortex 18, 1094-1111.

Borra, E., and Rockland, K. S. (2011). Projections to early visual areas $\mathrm{V} 1$ and V2 in the calcarine fissure from parietal association areas in the macaque. Front. Neuroanat. 5:35. doi: 10.3389/fnana.2011.00035

Bosco, A., Breveglieri, R., Chinellato, E., Galletti, C., and Fattori, P. (2010). Reaching activity in the medial posterior parietal cortex of monkeys is modulated by visual feedback. $J$. Neurosci. 30, 14773-14785.

Brett, M., Johnsrude, I. S., and Owen, A. M. (2002). The problem of functional localization in the human brain. Nat. Rev. Neurosci. 3, 243-249.

Buneo, C. A., and Andersen, R. A. (2006). The posterior parietal cortex: sensorimotor interface for the planning and online control of visually guided movements. Neuropsychologia 44, 2594-2606.

Buneo, C. A., Batista, A. P., Jarvis, M. R., and Andersen, R. A. (2008). Timeinvariant reference frames for parietal reach activity. Exp. Brain Res. 188, 77-89.

Buneo, C. A., Jarvis, M. R., Batista, A. P., and Andersen, R. A. (2002). Direct visuomotor transformations for reaching. Nature 416, 632-636.

Burnod, Y., Baraduc, P., BattagliaMayer, A., Guigon, E., Koechlin, Caminiti, R. (1999). Parieto-frontal E., Ferraina, S., Lacquaniti, F., and

\section{ACKNOWLEDGMENTS}

This work received partial financial support from the Italian Ministry for Education, University, and Research (MIUR; Grant PRIN-2008RBFNLH_004 to Piero P. Battaglini; http://prin.miur.it/).

coding of reaching: an integrated framework. Exp. Brain Res. 129, 325-346.

Busan, P., Barbera, C., Semenic, M., Monti, F., Pizzolato, G., Pelamatti, G., and Battaglini, P. P. (2009a). Effect of transcranial magnetic stimulation (TMS) on parietal and premotor cortex during planning of reaching movements. PLoS ONE 4:e4621. doi: 10.1371/journal.pone.0004621

Busan, P., Jarmolowska, J., Semenic, M. Monti, F., Pelamatti, G., Pizzolato, G., and Battaglini, P. P. (2009b) Involvement of ipsilateral parietooccipital cortex in the planning of reaching movements: evidence by TMS. Neurosci. Lett. 460, 112-116.

Busan, P., Monti, F., Semenic, M. Pizzolato, G., and Battaglini, P. P. (2009c). Parieto-occipital cortex and planning of reaching movements: a transcranial magnetic stimulation study. Behav. Brain Res. 201, 112-119.

Calton, J. L., Dickinson, A. R., and Snyder, L. H. (2002). Non-spatial, motor-specific activation in posterior parietal cortex. Nat. Neurosci. 5 , 580-588.

Casali, A. G., Casarotto, S., Rosanova, M., Mariotti, M., and Massimini, M (2010). General indices to characterize the electrical response of the cerebral cortex to TMS. Neuroimage 49, 1459-1468.

Chang, S. W. C., Dickinson, A. R., and Snyder, L. H. (2008). Limb-specific representation for reaching in the posterior parietal cortex. J. Neurosci. 28, 6128-6140.

Chen, X., Scangos, K. W., and Stuphorn, V. (2010). Supplementary motor area exerts proactive and reactive control of arm movements. J. Neurosci. 30, 14657-14675.

Chikazoe, J., Jimura, K., Hirose, S. Yamashita, K., Miyashita, Y., and Konishi, S. (2009). Preparation to inhibit a response complement response inhibition during performance of a stop-signal task. J. Neurosci. 29, 15870-15877.

Ciavarro, M., and Ambrosini, E. (2011). Specificity for reach planning in the human PPC. J. Neurosci. 31, 2719-2720.

Cisek, P., and Kalaska, J. F. (2010). Neural mechanisms for interacting with a world full of action choices. Annu. Rev. Neurosci. 33, 269-298.

Cohen, Y. E., and Andersen, R. A. (2002). A common reference frame for movement plans in the posterior parietal cortex. Nat. Rev. Neurosci. 3, 553-562.

Connolly, J. D., Andersen, R. A., and Goodale, M. A. (2003). FMRI evidence for a "parietal reach region" in the human brain. Exp. Brain Res. 153, 140-145.

Coxon, J. P., Stinear, C. M., and Byblow, W. D. (2006). Intracortical inhibition during volitional inhibition of prepared action. J. Neurophysiol. 95, 3371-3383.

Coxon, J. P., Stinear, C. M., and Byblow, W. D. (2009). Stop and go: the neural basis of selective movement prevention. J. Cogn. Neurosci. 21, 1193-1203

Cui, H., and Andersen, R. A. (2011) Different representations of potential and selected motor plans by distinct parietal areas. J. Neurosci. 31, 18130-18136.

Davare, M., Andrei, M., Cosnard, G., Thonnard, J. L., and Olivier, E. (2006). Dissociating the role of ventral and dorsal premotor cortex in precision grasping. J. Neurosci. 26, 2260-2268.

Davare, M., Rothwell, J. C., and Lemon, R. N. (2010). Causal connectivity between the human anterior intraparietal area and premotor cortex during grasp. Curr. Biol. 20, 176-181.

Delorme, A., and Makeig, S. (2004). EEGLAB: an open source toolbox for analysis of single-trial EEG dynamics including independent component analysis. J. Neurosci. Methods 134, 9-21.

Desmurget, M., Prablanc, C., Arzi, M., Rossetti, Y., Paulignan, Y., and Urquizar, C. (1996). Integrated control of hand transport and orientation during prehension movements. Exp. Brain Res. 110, 265-278.

Desmurget, M., and Sirigu, A. (2009). A parietal-premotor network for movement intention and motor awareness. Trends Cogn. Sci. 13, 411-419.

Desmurget, M., Turner, R. S., Prablanc, C., Russo, G. S., Alexander, G. E., and Grafton, S. T. (2005). Updating target location at the end of an orienting saccade affects 
the characteristics of simple point-to-point movements. J. Exp. Psychol. Hum. Percept. Perform. 31, 1510-1536.

Fattori, P., Gamberini, M., Kutz, D. F., and Galletti, C. (2001). 'Armreaching' neurons in the parietal area V6A of the macaque monkey. Eur. J. Neurosci. 13, 2309-2313.

Fattori, P., Kutz, D. F., Breveglieri, R., Marzocchi, N., and Galletti, C. (2005). Spatial tuning of reaching activity in the medial parietooccipital cortex (area V6A) of macaque monkey. Eur. J. Neurosci. 22, 956-972.

Fernandez-Ruiz, J., Goltz, H. C., DeSouza, J. F. X., Vilis, T., and Crawford, J. D. (2007). Human parietal "reach region" primarily encodes intrinsic visual direction, not extrinsic movement direction, in a visual-motor dissociation task. Cereb. Cortex 17, 2283-2292.

Ferraina, S., Garasto, M. R., BattagliaMayer, A., Ferraresi, P., Johnson, P. B., Lacquaniti, F., and Caminiti, R. (1997). Visual control of hand reaching movement: activity in parietal area 7 m. Eur. J. Neurosci. 9, 1090-1095.

Filimon, F., Nelson, J. D., Huang, R. S., and Sereno, M. I. (2009). Multiple parietal reach regions in humans: cortical representations for visual and proprioceptive feedback during on-line reaching. J. Neurosci. 29, 2961-2971.

Fuchs, M., Kastner, J., Wagner, M., Hawes, S., and Ebersole, J. S. (2002). A standardized boundary element method volume conductor model. Clin. Neurophysiol. 113, 702-712.

Galletti, C., Gamberini, M., Kutz, D. F., Fattori, P., Luppino, G., and Matelli, M. (2001). The cortical connections of area V6, an occipitoparietal network processing visual information. Eur. J. Neurosci. 13, 1572-1588.

Gamberini, M., Passarelli, L., Fattori, P., Zucchelli, M., Bakola, S., Luppino, G., and Galletti, C. (2009). Cortical connections of the visuomotor parietooccipital area V6Ad of the macaque monkey. J. Comp. Neurol. $513,622-642$.

Glover, S. (2004). Separate visual representations in the planning and control of action. Behav. Brain Sci. 27, 3-24.

Goodale, M. A. (1988). Hemispheric differences in motor control. Behav. Brain Res. 30, 203-214.

Goodale, M. A., and Milner, A. D. (1992). Separate visual pathways for perception and action. Trends Neurosci. 15, 20-25.
Goodale, M. A., and Milner, A. D. (2004). Plans for action. Behav. Brain Sci. 27, 37-41.

Graziano, M. S. A., Cooke, D. F., and Taylor, C. S. R. (2000). Coding the location of the arm by sight. Science 290, 1782-1786.

Greicius, M. D., Supekar, K., Menon, V., and Dougherty, R. F. (2009). Resting-state functional connectivity reflects structural connectivity in the default mode network. Cereb. Cortex 19, 72-78.

Haaland, K. Y., and Harrington, D. L. (1989). Hemispheric control of the initial and corrective components of aiming movements. Neuropsychologia 27, 961-969.

Hagmann, P., Cammoun, L., Gigandet, X., Meuli, R., Honey, C. J., and Wedeen, V. J. (2008). Mapping the structural core of human cerebral cortex. PLoS Biol. 6:1479-1493. doi: 10.1371/journal.pbio.0060159

Herwig, U., Satrapi, P., and SchönfeldtLecuona, C. (2003). Using the international 10-20 EEG system for positioning of transcranial magnetic stimulation. Brain Topogr. 16, 95-99.

Himmelbach, M., and Karnath, H. O. (2005). Dorsal and ventral stream interaction: contributions from optic ataxia. J. Cogn. Neurosci. 17, 632-640.

Hoshi, E., and Tanji, J. (2007). Distinctions between dorsal and ventral premotor areas: anatomical connectivity and functional properties. Curr. Opin. Neurobiol. 17, 234-242.

Iacoboni, M. (2006). Visuo-motor integration and control in the human posterior parietal cortex: evidence from TMS and fMRI. Neuropsychologia 44, 2691-2699.

Ilmoniemi, R. J., and Kicić, D. (2010). Methodology for combined TMS and EEG. Brain Topogr. 22, 233-248.

Jackson, S. R., Newport, R., Husain, M., Fowlie, J. E., O’Donoghue, M., and Bajaj, N. (2009). There may be more to reaching than meets the eye: re-thinking optic ataxia. Neuropsychologia 47, 1397-1408.

Jeannerod, M., Arbib, M. A., Rizzolatti, G., and Sakata, H. (1995). Grasping objects: the cortical mechanisms of visuomotor transformation. Trends Neurosci.18, 314-320.

Johnson, P. B., Ferraina, S., Bianchi, L., and Caminiti, R. (1996). Cortical networks for visual reaching. Physiological and anatomical organization of frontal and parietal lobe arm regions. Cereb. Cortex 6, 102-119.

Jung, T. P., Makeig, S., Humphries, C., Lee, T. W., McKeown, M. J., Iragui,
V., and Sejnowski, T. J. (2000). Removing electroencephalographic artifacts by blind source separation. Psychophysiology 37, 163-178.

Jurcak, V., Tsuzuki, D., and Dan, I. (2007). 10/20, 10/10, and 10/5 systems revisited: their validity as relative head-surface-based positioning systems. Neuroimage 34, 1600-1611.

Kalaska, J. F., and Crammond, D. J. (1995). Deciding not to go: neuronal correlates of response selection in a go/nogo task in primate premotor and parietal cortex. Cerebr. Cortex 5, 410-428.

Karch, S., Mulert, C., Thalmeier, T., Lutz, J., Leicht, G., Meindl, T., Möller, H. J., Jäger, L., and Pogarell, O. (2009). The free choice whether or not to respond after stimulus presentation. Hum. Brain Mapp. 30, 2971-2985.

Kastner, S., Demmer, I., and Ziemann, U. (1998). Transient visual field defect induced by transcranial magnetic stimulation over human occipital lobe. Exp. Brain Res. 118, 19-26.

Kertzman, C., Schwarz, U., Zeffiro, T. A., and Hallett, M. (1997). The role of posterior parietal cortex in visually guided reaching movements in humans. Exp. Brain Res. 114 170-183.

Khan, A. Z., Crawford, J. D., Blohm, G., Urquizar, C., Rossetti, Y., and Pisella, L. (2007). Influence of initial hand and target position on reach errors in optic ataxia and normal subjects. J. Vis. 7, 1-16.

Koch, G., Cercignani, M., Pecchioli, C. Versace, V., Oliveri, M., Caltagirone, C., Rothwell, J., and Bozzali, M. (2010). In vivo definition of parietomotor connections involved in planning of grasping movements. Neuroimage 51, 300-312.

Koch, G., Del Olmo, M. F., Cheeran, B., Schippling, S., Caltagirone, C., Driver, J., and Rothwell, J. C. (2008). Functional interplay between posterior parietal and ipsilateral motor cortex revealed by twin-coil transcranial magnetic stimulation during reach planning toward contralateral space. J. Neurosci. 28, 5944-5953.

Lancaster, J. L., Woldorff, M. G. Parsons, L. M., Liotti, M., Freitas, C. S., Rainey, L., Kochunov, P. V., Nickerson, D., Mikiten, S. A. and Fox, P. T. (2000). Automated Talairach Atlas labels for functional brain mapping. Hum. Brain Mapp. 10, 120-131.

Lindner, A., Iyer, A., Kagan, I., and Andersen, R. A. (2010). Human posterior parietal cortex plans where to reach and what to avoid. J. Neurosci. 30, 11715-11725.

Makuuchi, M., Someya, Y., Ogawa, S., and Takayam, Y. (2012). Hand shape selection in pantomimed grasping: interaction between the dorsal and the ventral visual streams and convergence on the ventral premotor area. Hum. Brain Mapp. 33, 1821-1833.

Marconi, B., Genovesio, A., BattagliaMayer, A., Ferraina, S., Squatrito, S., Molinari, M., Lacquaniti, F., and Caminiti, R. (2001). Eye-hand coordination during reaching. I Anatomical relationship between parietal and frontal cortex. Cereb. Cortex 11, 513-527.

Mars, R. B., Jbabdi, S., Sallet, J., O’Reilly, J. X., Croxson, P. L., Olivier, E., Noonan, M. A. P., Bergmann, C., Mitchell, A. S., Baxter, M. G., Behrens, T. E., Johansen-Berg, H., Tomassini, V., Miller, K. L., and Rushworth, M. F. S. (2011). Diffusion-weighted imaging tractography-based parcellation of the human parietal cortex and comparison with human and macaque resting-state functional connectivity. J. Neurosci. 31, 4087-4100.

Massimini, M., Ferrarelli, F., Huber, R., Esser, S. K., Singh, H., and Tononi, G. (2005). Breakdown of cortical effective connectivity during sleep. Science 309, 2228-2232.

Matsuzaka, Y., and Tanji, J. (1996). Changing directions of forthcoming arm movements: neuronal activity in the presupplementary and supplementary motor area of monkey cerebral cortex. J. Neurophysiol. 76, 2327-2342.

Mazziotta, J., Toga, A., Evans, A., Fox, P., Lancaster, J., Zilles, K., Woods, R., Paus, T., Simpson, G., Pike, B., Holmes, C., Collins, L., Thompson, P., MacDonald, D., Iacoboni, M., Schormann, T., Amunts, K., Palomero-Gallagher, N., Geyer, S., Parsons, L., Narr, K., Kabani, N., Le Goualher, G., Boomsma, D., Cannon, T., Kawashima, R., and Mazoyer, B. (2001). A probabilistic atlas and reference system for the human brain: International Consortium for Brain Mapping (ICBM). Philos. Trans. R. Soc. Lond. B Biol. Sci. 356, 1293-1322.

Medendorp, W. P., Goltz, H. C., Crawford, J. D., and Vilis, T. (2005). Integration of target and effector information in human posterior parietal cortex for the planning of action. J. Neurophysiol. 93 954-962.

Medendorp, W. P., Goltz, H. C., Vilis, T., and Crawford, J. D. (2003) 
Gaze-centered updating of visual space in human parietal cortex. $J$. Neurosci. 23, 6209-6214.

Milner, D., and Goodale, M. (2006). The Visual Brain in Action. Oxford, USA: Oxford University Press.

Miniussi, C., Ruzzoli, M., and Walsh, V. (2010). The mechanism of transcranial magnetic stimulation in cognition. Cortex 46, 128-130.

Mirabella, G., Iaconelli, S., Romanelli, P., Modugno, N., Lena, F., Manfredi, M., and Cantore, G. (2012). Deep brain stimulation of subthalamic nuclei affects arm response inhibition in Parkinson's patients. Cereb. Cortex 22, 1124-1132.

Mirabella, G., Pani, P., and Ferraina, S. (2008). Influence of context on reaction and movement times. Cogn. Neuropsychol. 25, 996-1010.

Mirabella, G., Pani, P., and Ferraina, S. (2011). Neural correlates of cognitive control of reaching movements in the dorsal premotor cortex of rhesus monkeys. J. Neurophysiol. 106, 1454-1466.

Mirabella, G., Pani, P., Parè, M., and Ferraina, S. (2006). Inhibitory control of reaching movements in humans. Exp. Brain Res. 174, 240-255.

Mon-Williams, M., and McIntosh, R. D. (2000). A test between two hypotheses and a possible third way for the control of prehension. Exp. Brain Res. 134, 268-273.

Naranjo, J. R., Brovelli, A., Longo, R., Budai, R., Kristeva, R., and Battaglini, P. P. (2007). EEG dynamics of the frontoparietal network during reaching preparation in humans. Neuroimage 34, 1673-1682.

Nichols, T. E., and Holmes, P. A. (2002). Nonparametric permutation tests for functional neuroimaging; a primer with examples. Hum. Brain Mapp. 15, 1-25.

Nikouline, V., Ruohonen, J., and Ilmoniemi, R. J. (1999). The role of the coil click in TMS assessed with simultaneous EEG. Clin. Neurophysiol. 110, 1325-1328.

Oldfield, R. C. (1971). The assessment and analysis of handedness: the Edinburgh inventory. Neuropsychologia 9, 97-113.

Oostenveld, R., and Praamstra, P. (2001). The five percent electrode system for high-resolution EEG and ERP measurements. Clin. Neurophysiol. 112, 713-719.

Pascual-Marqui, R. D. (2002). Standardized low resolution brain electromagnetic tomography: a new method for localizing electrical activity in the brain. Int. J. Psychophysiol. 18, 49-65.

Passarelli, L., Rosa, M. G., Gamberini, M., Bakola, S., Burman, K. J., Fattori, P., and Galletti, C. (2011). Cortical connections of area V6Av in the macaque: a visual-input node to the eye/hand coordination system. J. Neurosci. 31, 1790-1801.

Paus, T., Sipila, P. K., and Strafella, A. P. (2001). Synchronization of neuronal activity in the human primary motor cortex by transcranial magnetic stimulation: an EEG study. $J$. Neurophysiol. 86, 1983-1990.

Perenin, M. T., and Vighetto, A. (1988). Optic ataxia: a specific disruption in visuomotor mechanisms. I. Different aspects of the deficit in reaching for objects. Brain 111, 643-674.

Pesaran, B., Nelson, M. J., and Andersen, R. A. (2006). Dorsal premotor neurons encode the relative position of the hand, eye and goal during reach planning. Neuron 51, 125-134.

Pisella, L., Binkofski, F., Lasek, K., Toni, I., and Rossetti, Y. (2006). No double-dissociation between optic ataxia and visual agnosia: multiple sub-streams for multiple visuo-manual integrations. Neuropsychologia 44, 2734-2748.

Prado, J., Clavagnier, S., Otzenberger, H., Scheiber, C., Kennedy, H., and Perenin, M. T. (2005). Two cortical systems for reaching in central and peripheral vision. Neuron 48, 849-858.

Raichle, M. E., MacLeod, A. M., Snyder, A. Z., Powers, W. J., Gusnard, D. A., and Shulman, G. L. (2001). A default mode of brain function. Proc. Natl. Acad. Sci. U.S.A. 98, 676-682.

Raichle, M. E., and Snyder, A. Z. (2007). A default mode of brain function: a brief history of an evolving idea. Neuroimage 237, 1083-1090.

Randerath, J., Goldenberg, G., Spijkers, W., Li, Y., and Hermsdörfer, J. (2010). Different left brain regions are essential for grasping a tool compared with its subsequent use. Neuroimage 53, 171-180.

Reichenbach, A., Bresciani, J. P., Peer, A., Bülthoff, H. H., and Thielscher, A. (2011). Contributions of the PPC to online control of visually guided reaching movements assessed with fMRI-guided TMS. Cereb. Cortex 21, 1602-1612.

Rice, N. J., Tunik, E., and Grafton, S. T. (2006). The anterior intraparietal sulcus mediates grasp execution, independent of requirement to update: new insights from transcranial magnetic stimulation. J. Neurosci. 26, 8176-8182.

Riddoch, G. (1935). Visual disorientation in homonymous half-fields. Brain 58, 376-382.

Rushworth, M. F. S., Johansen-Berg, H., Göbel, S. M., and Devlin, J. T. (2003). The left parietal and premotor cortices: motor attention and selection. Neuroimage 20, S89-S100.

Rushworth, M. F. S., Krams, M., and Passingham, R. E. (2001). The attentional role of the parietal cortex: the distinct lateralization and localization of motor attention in the human brain. J. Cogn. Neurosci. 13, 698-710.

Sawaki, L., Okita, T., Fukiwara, M., and Mizumo, K. (1999). Specific and non-specific effects of transcranial magnetic stimulation upon simple and go/no-go reaction time. Exp. Brain Res. 127, 402-408.

Schenk, T., and Milner, A. D. (2006). Concurrent visuomotor behavior improves form discrimination in a patient with visual form agnosia. Eur. J. Neurosci. 24, 1495-1503.

Silvanto, J., and Muggleton, N. G. (2008). New light through old windows: moving beyond the "virtual lesion" approach to transcranial magnetic stimulation. Neuroimage 39, 549-552.

Smeets, J. B., and Brenner, E. (1999). A new view on grasping. Mot. Control 3, 237-271.

Snyder, L. H., Dickinson, A. R., and Calton, J. L. (2006). Preparatory delay activity in the monkey parietal reach region predicts reach reaction times. J. Neurosci. 26, 10091-10099.

Steinsträter, O., Sommer, J., Deppe, M., and Knecht, S. (2002). The Münster T2T-Converter. http:// www.neuro03.uni-muenster.de/ger/ t2tconv/

Stinear, C. M., Coxon, J. P., and Byblow, W. D. (2009). Primary motor cortex and movement prevention: where stop meets go. Neurosci. Biobehav. Rev. 33, 662-673.

Striemer, C., Locklin, J., Blangero, A., Rossetti, Y., Pisella, L., and Danckert, J. (2009). Attention for action? Examining the link between attention and visuomotor control deficits in a patient with optic ataxia. Neuropsychologia 47, 1491-1499.

Striemer, C. L., Chouinard, P. A., and Goodale, M. A. (2011). Programs for action in superior parietal cortex: a triple-pulse TMS investigation. Neuropsychologia 49, 2391-2399.
Swann, N. C., Cai, W., Conner, C. R., Pieters, T. A., Claffey, M. P., George, J. S., Aron, A. R., and Tandon, N. (2012). Roles for the pre-supplementary motor area and the right inferior frontal gyrus in stopping action: electrophysiological responses and functional and structural connectivity. Neuroimage 59, 2860-2870.

Swick, D., Ashley, V., and Turken, U. (2011). Are the neural correlates of stopping and not going identical? Quantitative meta-analysis of two response inhibition tasks. Neuroimage 56, 1655-1665.

Tannè, J., Boussaud, D., Boyer-Zeller, N., and Rouiller, E. M. (1995). Direct visual pathways for reaching movements in the macaque monkey. Neuroreport 29, 267-272.

Taylor, K. I., Stamatakis, E. A., and Tyler, L. K. (2009). Crossmodal integration of object features: voxel-based correlations in braindamaged patients. Brain 132, 671-683.

Trillenberg, P., Sprenger, A., Petersen, D., Kömpf, D., Heide, W., and Helmchen, C. (2007). Functional dissociation of saccade and hand reaching control with bilateral lesions of the medial wall of the intraparietal sulcus: implication for optic ataxia. Neuroimage 36, T69-T76.

Tunik, E., Frey, S. H., and Grafton, S. T. (2005). Virtual lesions of the anterior intraparietal area disrupt goaldependent on-line adjustments of grasp. Nat. Neurosci. 8, 505-511.

Ulloa, A., and Bullock, D. (2003). A neural network simulating human reach-grasp coordination by continuous updating of vector positioning commands. Neural Netw. 16, 1141-1160.

Valyear, K. F., and Culham, J. C. (2010). Observing learned object-specific functional grasps preferentially activates the ventral stream. J. Cogn. Neurosci. 22, 970-984.

Vesia, M., Prime, S. L., Yan, X., Sergio, L. E., and Crawford, J. D. (2010). Specificity of human parietal saccade and reach regions during transcranial magnetic stimulation. $J$. Neurosci. 30, 13052-13065.

Vesia, M., Yan, X., Henriques, D. Y., Sergio, L. E., and Crawford, J. D. (2008). Transcranial magnetic stimulation over human dorsal-lateral posterior parietal cortex disrupts integration of hand position signals into the reach plan. J. Neurophysiol. 100, 2005-2014.

Vingerhoets, G., Alderweireldt, A. S., Vandemaele, P., Cai, Q., Van der Haegen, L., Brysbaert, M., 
and Achten, E. (2011). Praxis and language are linked: evidence from co-lateralization in individuals with atypical language dominance. Cortex. doi: 10.1016/j.cortex.2011. 11.003. [Epub ahead of print].

Walsh, V., and Pascual-Leone, A. (2003). A Neurochronometrics of Mind. Cambridge, MA: The MIT Press.

Watanabe, J., Sugiura, M., Sato, K., Sato, Y., Maeda, Y., Matsue, Y., Fukuda, H., and Kawashima, R. (2002). The human prefrontal and parietal association cortices are involved in NO-GO performances: an event-related fMRI study. Neuroimage 17, 1207-1216.

Wheaton, L., Fridman, E., Bohlhalter, S., Vorbach, S., and Hallett, M. (2009). Left parietal activation related to planning, executing and suppressing praxis hand movements. Clin. Neurophysiol. 120, 980-986.

Zanon, M., Busan, P., Monti, F., Pizzolato, G., and Battaglini, P. P. (2010). Cortical connections between dorsal and ventral visual streams in humans: evidence by
TMS/EEG co-registration. Brain Topogr. 22, 307-317.

Conflict of Interest Statement: The authors declare that the research was conducted in the absence of any commercial or financial relationships that could be construed as a potential conflict of interest.

Received: 18 February 2012; accepted: 19 July 2012; published online: 08 August 2012.

Citation: Busan P, Zanon M, Vinciati F, Monti F, Pizzolato $G$ and Battaglini PP
(2012) Transcranial magnetic stimulation and preparation of visually-guided reaching movements. Front. Neuroeng. 5:18. doi: 10.3389/fneng.2012.00018

Copyright (c) 2012 Busan, Zanon, Vinciati, Monti, Pizzolato and Battaglini. This is an open-access article distributed under the terms of the Creative Commons Attribution License, which permits use, distribution and reproduction in other forums, provided the original authors and source are credited and subject to any copyright notices concerning any third-party graphics etc. 